\title{
Early Atherosclerosis in Rheumatoid Arthritis: A case Control Study
}

\author{
Sonaullah Shah, M.D., Nitin Gupta, M.D., Feroze Shaheen, M.D.,' Fayaz Ahmad Sofi, M.D., \\ Umar Hafiz, M.D., Rafi Ahmed Jan, M.D., Shawkat Ali Mufti, M.D., Bashir Ahmed Shah, M.D. \\ Department of Internal Medicine and 'Department of Radio-diagnosis, Sher-i-Kashmir Institute of Medical Sciences, Srinagar, Kashmir.
}

\section{A B S T R A C T}

\begin{abstract}
BACKGROUND: Atherosclerosis remains the major cause of death and premature disability in developed countries.
OBJECTIVES: To assess the prevalence of early (accelerated) atherosclerosis in Rheumatoid Arthritis (RA) patients in the absence of traditional risk factors and influence of various other parameters on it.

METHODS: The study was carried at a tertiary care university hospital in northern India (Kashmir) in year 2008-2009. Thirty nine patients in the age group of 25- 55 years with RA fulfilling the American College of Rheumatology (ACR) Modified criteria 1987 and a purposive sample of twenty healthy volunteers that served as controls were enrolled to judge any difference in the studied parameters. Subjects with other risk factors for atherosclerosis were excluded from the study. Disease Activity Score (DAS-28) was used to measure the disease activity. B-mode ultrasonography was used to measure carotid artery intima media thickness (CIMT) in both the groups.

RESULTS: RA patients presented with elevated CIMT in the age group of 41-50 years $(p=0.665)$ whereas volunteers had such tendency in the 5 th decade of life $(p=0.550)$. Duration of disease greater than 5 years also positively influenced the development of increased CIMT in the patient group ( $p$ 0.64). Patients in the RA group had a higher erythrocyte sedimentation rate $(E S R)$ and mean CIMT as compared to the controls $(p=0.000)$. RA patients had lower hemoglobin concentration when compared to age and sex matched controls. Intergroup comparison in patients with normal and increased CIMT showed that increased BMI, elevated triglyceride (TG) concentration and raised ESR influenced the development of CIMT which on binary logistic regression showed that TG $(p=0.043)$ and BMI $(p=0.053)$ had influence in progression of CIMT.

CONCLUSION: Rheumatoid Arthritis patients have definite evidence of early (accelerated) atherosclerosis due to inflammation even in this ethnic population. BMl and serum triglycerides even in normal range have noteworthy influence in acceleration of atherosclerosis in them. B-mode ultrasonography is simple, non-invasive, and one of the sensitive methods to detect earlier atherosclerotic changes in them. JMS 2012;15(2):106-10
\end{abstract}

Key words: Rheumatoid arthritis, atherosclerosis, carotid intima media thickness, B-mode ultrasonography

Atherosclerosis remains the major cause of death and premature disability in developed societies. ${ }^{1}$ It is now considered an immuno-inflammatory process. Apart from traditional risk factors like smoking, hypertension, diabetes mellitus, dyslipidemia, several novel inflammation related risk factors are currently implicated in the pathophysiology of

\section{Correspondence:}

Dr. Fayaz Ahmad Sofi

Department of Internal Medicine,

Sher-i-Kashmir Institute of Medical Sciences, Srinagar, Kashmir.

E-mail:fayazkanjwal@rediffmail.com atherosclerosis. Among these novel risk factors, rheumatoid arthritis (RA) has been implicated to cause accelerated atherosclerosis and increased cardiovascular morbidity and mortality. ${ }^{2}$

Atherosclerosis is emerging as an important complication of rheumatoid arthritis with coronary artery disease as major cause of mortality. Patients with RA have reduced life expectancy and high cardiovascular morbidity and mortality as compared to that in the general population. ${ }^{3-7}$ Indian population is also at increased risk of developing atherosclerotic coronary artery disease. Indian data on this 
aspect of RA is sparse and there is no such study available in this ethnic population till date. Keeping this in mind, we conducted a prospective study to assess the prevalence of atherosclerosis in RA patients in the absence of traditional risk factors and influence of various other factors on it.

\section{Methods}

The study was carried at a tertiary care university hospital in northern India (Kashmir) from 2008-2009. Thirty nine patients in the age group of 20- 54 years with RA fulfilling the American College of Rheumatology(ACR) Modified criteria 1987 were taken up for the study. ${ }^{8}$ Besides; twenty healthy volunteers were enrolled to judge any difference in the studied parameters.

Smokers, males with age $<20$ and $\geq 45$ years, females $<20$ and $\geq 55$ years and patients having a BMI of $>30$ were excluded from the study. Besides patients having a history of coronary artery disease (CAD) or stroke, a history of CAD or stroke in first degree relatives in males $>55$ years and females $>65$ years, diabetes mellitus, hypertension $(\mathrm{BP} \geq 140 / 90$ $\mathrm{mmHg}$ ), hyperlipidemia (fasting total cholesterol of $>200$ $\mathrm{mg} / \mathrm{dL}$; fasting serum triglycerides $>150 \mathrm{mg} / \mathrm{dL}$ ) were also excluded from the study. ${ }^{1}$

Formal written consent was taken from the studied subjects prior to recruitment in the study. Also the study was approved by the hospital ethical committee. A detailed history and physical examination was performed in all the subjects. Disease Activity Score-28 (DAS- 28) was used to measure the disease activity with a DAS-28 score of $\geq 3$.2$<5.1$ classified as mild and a DAS- 28 score of $\geq 5.1$ classified as severe disease. ${ }^{9}$ Patient was said to have diabetes mellitus if it was diagnosed by the physician, patient was taking antidiabetic medications or had a fasting blood sugar $\geq 126 \mathrm{mg} \%$ or a 2 hour post 75 gram oral glucose load $\geq 200 \mathrm{mg} \%$ or a random blood glucose of $\geq 200 \mathrm{mg} \%$. CAD was said to be present if the patient had a history of angina or myocardial infarction or if the patient had been put on anti-ischemic medication by the physician. History of stroke or transient ischemic attack (TIA) in the patient or his or her first degree relative was determined by historical evidence and previous records.

B mode ultrasonography or color Doppler was used to measure CIMT in both the groups. A single expert radiologist conducted the test to exclude any individual bias in interpretation.

The subjects were examined in supine position in the bed. Common carotid arteries on both the sides were scanned along the three different planes in longitudinal axis and in a cross sectional axis. CIMT was measured on a longitudinal scan of the carotid artery at a point $10 \mathrm{~mm}$ proximal from beginning of the dilatation of the carotid bulb. This scan pattern was characterized by two echogenic lines separated by hypo-echoic and anechoic space. Outer line corresponded to the medial-adventitial border and the inner line corresponded to the luminal-intimal border. Distance between two parallel lines represented the CIMT as the white area. Mean CIMT values $( \pm 2 S D)$ above the mean CIMT values of volunteers were taken as abnormal.,10

Statistical analysis: Data was described as mean \pm SD and percentages. Univariate analysis was done by Student's t-test and Mann-Whitney's $U$ test. The factors with $p$ value of $<0.05$ on univariate analysis were subjected for multivariate analysis (Binary Logistic Regression) to evaluate best predictors in the study group. Statistical package SPSS-16.0 was used for data analysis.

\section{Results}

Age of patients ranged from 20-50 years (37.7 \pm 6.9$)$ and in controls $21-53$ years $(36.1 \pm 11.1)$. Females constituted $71.8 \%$ of cases and $40 \%$ of controls. Gender ratio of the respective two groups was $1: 2.3$ and $1.5: 1$ respectively. Duration of disease ranged from 1-20 years (mean 5.7 \pm 4.1 years). $94.9 \%$ of patients were on some form of non-steroidal anti-Inflammatory drugs (NSAIDs), $48.7 \%$ on disease modifying anti-rheumatic drugs (DMARDs), 59\% on steroids and $7.7 \%$ on ayurvedic medicines. Rheumatoid factor was positive in 34(87.4\%) and 35(89.7\%) tested positive for $\mathrm{C}$ - reactive protein (CRP). There was evidence of X-ray erosions in X-rays of hands in 14(35.9\%). Mean CIMT was maximum in the age group of $41-50$ years $(p$ $0.665)$, but in the controls it was maximum in the age group of 51-60 years $(p=0.55)$. Mean CIMT increased in patients after the age of 40 years and was higher in patients with disease duration of greater than 5 years $(p=0.64)$. Gender difference was insignificant in cases $(p=0.240)$ and controls $(p=0.729)$.

Haemoglobin $(\mathrm{Hb})$, erythrocyte sedimentation rate (ESR), mean CIMT and female gender showed statistically significant difference between study and control group $(p<0.05)$ (Table 1).

Additionally, CIMT among the subjects in the study group was dichotomized into raised ( $\geq 2 \mathrm{SD}$ from mean of controls) and normal ( $<2 \mathrm{SD}$ from mean of controls) groups. These two groups were then subjected to intergroup comparison. BMI, TG and ESR were found to be significantly different among the two groups.. The predicted three parameters were further evaluated by binary logistic regression that showed TG $(p=0.043)$ and BMI $(p=0.053)$ having statistically significant influence in progression of CIMT (Table 2).

DAS-28 scoring did not show any statistical influence on CIMT in RA patients ( $p$ 0.707). Rheumatoid factor ( $p$ $=0.840)$, CRP status $(p=0.540)$ and presence of radiological abnormalities $(p=0.503)$ as well did not influence mean CIMT values. Patients taking NSAIDs, DMARDs and steroids showed no significant difference in mean CIMT in 
TABLE 1. Baseline parameters in the study and control groups

\begin{tabular}{|c|c|c|c|}
\hline & Study $(\mathrm{n}=39)$ & Control $(n=20)$ & $p$ value \\
\hline Age(yrs) & $\begin{array}{c}37.7 \pm 6.9 \\
(21,50)\end{array}$ & $\begin{array}{c}36.1 \pm 11.1 \\
(20,53)\end{array}$ & 0.481 \\
\hline Female & $28(71.8)$ & 0.019 & \\
\hline NSAIDS & $37(94.9)$ & $0(0.0)$ & 0.000 \\
\hline DMARDS & $19(48.7)$ & $0(0.0)$ & 0.000 \\
\hline Steroids & $23(59.0)$ & $0(0.0)$ & 0.000 \\
\hline Ayurvedic & $3(7.7)$ & $0(0.0)$ & 0.000 \\
\hline \multirow[t]{2}{*}{$\operatorname{BMI}\left(\mathrm{kg} / \mathrm{m}^{2}\right)$} & $24.6 \pm 2.5$ & $23.7 \pm 2.8$ & \\
\hline & $(17.8,28.6)$ & $(19.0,27.9)$ & 0.324 \\
\hline \multirow[t]{2}{*}{$\mathrm{Hb}(\mathrm{g} / \mathrm{dl})$} & $11.1 \pm 1.8$ & $12.5 \pm 1.8$ & \\
\hline & $(7.3,15)$ & $(9.1,15.5)$ & 0.009 \\
\hline \multirow[t]{2}{*}{ TLC(cumm) } & $7.7 \pm 2.6$ & $6.7 \pm 1.8$ & \\
\hline & $(4.1,15.0)$ & $(4.4,11.0)$ & 0.112 \\
\hline $\mathrm{ESR}(\mathrm{mm} / \mathrm{h})$ & $\begin{array}{c}41.6 \pm 18.2 \\
(13,92)\end{array}$ & $\begin{array}{c}23.7 \pm 5.7 \\
(13,40)\end{array}$ & 0.000 \\
\hline CRP(mg/l) & $35(89.7)$ & $0(0.0)$ & 0.000 \\
\hline $\mathrm{RF}(\mathrm{IU} / \mathrm{ml})$ & $34(87.2)$ & $0(0.0)$ & 0.000 \\
\hline BSF(mg/dl) & $\begin{array}{c}89.5 \pm 12.3 \\
(61,116)\end{array}$ & $\begin{array}{c}91.7 \pm 17.2 \\
(68,146)\end{array}$ & 0.591 \\
\hline Urea(mg/dl) & $\begin{array}{c}35.0 \pm 9.0 \\
(20,58)\end{array}$ & $\begin{array}{c}34.6 \pm 9.5 \\
(23,51)\end{array}$ & 0.888 \\
\hline Creatinine(mg/dl) & $\begin{array}{l}0.8 \pm 0.2 \\
(0.4,1.3)\end{array}$ & $\begin{array}{l}(0.6,0.9) \\
0.8 \pm 0.1\end{array}$ & 0.549 \\
\hline $\mathrm{TG}(\mathrm{mg} / \mathrm{dl})$ & $\begin{array}{c}126.1 \pm 17.1 \\
(90,150)\end{array}$ & $\begin{array}{c}126.4 \pm 13.3 \\
(95,144)\end{array}$ & 0.959 \\
\hline $\mathrm{CHOL}(\mathrm{mg} / \mathrm{dl})$ & $\begin{array}{c}125.2 \pm 14.9 \\
(98,149)\end{array}$ & $\begin{array}{c}127.3 \pm 14.4 \\
(95,147)\end{array}$ & 0.632 \\
\hline Mean cIMT & $\begin{array}{c}0.6 \pm 0.1 \\
(0.4,0.9)\end{array}$ & $\begin{array}{l}0.5 \pm 0.1 \\
(0.3,0.6)\end{array}$ & 0.000 \\
\hline Erosions & $14(35.9)$ & $0(0.0)$ & 0.000 \\
\hline \multicolumn{4}{|c|}{$\begin{array}{l}\text { Note: Quantitative parameters are expressed as mean } \pm S D \text { and the } \\
\text { subsequent values separated by a comma within parenthesis represen } \\
\text { greatest lower bound and least upper bound of the respective variable. } \\
\text { Otherwise the numerals associated in parenthesis represent respective } \\
\text { frequency and its percentage. }\end{array}$} \\
\hline \multicolumn{4}{|c|}{$\begin{array}{l}\text { comparative analysis (Table 2). Results of multivariage } \\
\text { analysis are shown in table } 3 .\end{array}$} \\
\hline \multicolumn{4}{|c|}{ TABLE 3. Results of multivariate analysis } \\
\hline \multicolumn{3}{|c|}{ Score } & \\
\hline \multicolumn{2}{|l|}{ BMI } & & \\
\hline \multicolumn{2}{|l|}{ ESR } & & \\
\hline \multicolumn{2}{|l|}{ TG } & & \\
\hline
\end{tabular}

\section{Discussion}

Forty percent of RA patients have extra articular manifestations of which $15 \%$ are severe. ${ }^{11}$ Increasing attention is now paid to accelerated atherosclerosis in RA. Both traditional and inflammation related risk factors contribute to atherosclerosis in them. We sought evidence of atherosclerosis by B-mode carotid ultrasonography in patients of RA by measuring CIMT, which is simple, costeffective and one of the sensitive methods although with some limitations in focal lesions. This non-invasive tool is
TABLE 2. Correlation of CIMT across respective parameters among the study group

\begin{tabular}{|c|c|c|c|}
\hline & $\begin{array}{c}\text { Raised CIMT } \\
(\mathrm{n}=25)\end{array}$ & $\begin{array}{l}\text { Normal dIMT } \\
(\mathrm{n}=14)\end{array}$ & $p$ value \\
\hline Female & $18(72.0)$ & $10(71.4)$ & 0.970 \\
\hline Duration(yrs) & $5.4 \pm 4.0(0,15)$ & $5.1 \pm 5.7(0,20)$ & 0.814 \\
\hline NSAIDS & $24(96.0)$ & $13(92.9)$ & 0.674 \\
\hline DMARDS & $12(48.0)$ & $7(50.0)$ & 0.906 \\
\hline Steroids & $15(60.0)$ & $8(57.1)$ & 0.864 \\
\hline Ayurvedic & $3(12.0)$ & $0(0.0)$ & 0.183 \\
\hline $\operatorname{BMI}\left(\mathrm{kg} / \mathrm{m}^{2}\right)$ & $\begin{array}{c}25.1 \pm 2.2 \\
(18.7,28.6)\end{array}$ & $\begin{array}{c}23.3 \pm 2.8 \\
(17.8 .26 .7)\end{array}$ & 0.038 \\
\hline DAS- 28 & $\begin{array}{l}6.6 \pm 1.2 \\
(3.7,8.4)\end{array}$ & $\begin{array}{l}6.5 \pm 1.2 \\
(4.1 .8 .4)\end{array}$ & 0.707 \\
\hline $\mathrm{Hb}(\mathrm{g} / \mathrm{dl})$ & $\begin{array}{l}10.8 \pm 1.6 \\
(7.3,14.8)\end{array}$ & $\begin{array}{l}11.7 \pm 1.9 \\
(9.2,15.0)\end{array}$ & 0.121 \\
\hline $\mathrm{TLC} / \mu \mathrm{l}$ & $\begin{array}{c}7.5 \pm 2.4 \\
(4.1,15.0)\end{array}$ & $\begin{array}{c}8.2 \pm 2.9 \\
(4.2,14.5)\end{array}$ & 0.405 \\
\hline $\operatorname{ESR}(\mathrm{mm} / \mathrm{h})$ & $\begin{array}{c}46.2 \pm 18.8 \\
(13,92)\end{array}$ & $\begin{array}{c}33.2 \pm 14.3 \\
(16,60)\end{array}$ & 0.030 \\
\hline CRP(mg/l) & $23(92.0)$ & $12(85.7)$ & 0.540 \\
\hline $\operatorname{RF}(\mathrm{IU} / \mathrm{ml})$ & $22(88.0)$ & 12 (85.7) & 0.840 \\
\hline $\mathrm{BSF}(\mathrm{mg} / \mathrm{dl})$ & $\begin{array}{c}88.7 \pm 10.2 \\
(61,109)\end{array}$ & $\begin{array}{c}91.1 \pm 16.3 \\
(61,116)\end{array}$ & 0.603 \\
\hline Urea(mg/dl) & $\begin{array}{c}34.4 \pm 8.1 \\
(20,58)\end{array}$ & $\begin{array}{c}36.4 \pm 11.3 \\
(22,55)\end{array}$ & 0.575 \\
\hline Creatinine(mg/dl) & $\begin{array}{l}0.8 \pm 0.2 \\
(0.5,1.3)\end{array}$ & $\begin{array}{l}0.7 \pm 0.2 \\
(0.4,1.0)\end{array}$ & 0.153 \\
\hline $\mathrm{TG}(\mathrm{mg} / \mathrm{dl})$ & $\begin{array}{c}130.3 \pm 11.2 \\
(110,150)\end{array}$ & $\begin{array}{c}117.7 \pm 23.5 \\
(90,150)\end{array}$ & 0.044 \\
\hline $\mathrm{CHOL}(\mathrm{mg} / \mathrm{dl})$ & $\begin{array}{c}125.0 \pm 14.4 \\
(98,149)\end{array}$ & $\begin{array}{c}125.7 \pm 16.4 \\
(101,148)\end{array}$ & 0.897 \\
\hline Erosions & $8(32.0)$ & $6(42.9)$ & 0.503 \\
\hline
\end{tabular}

Note: Quantitative parameters are expressed as mean \pm SD and the subsequent values separated by a comma within parenthesis represent greatest lower bound and least upper bound of the respective variable. Otherwise the numerals associated in parenthesis represent respective frequency and its percentage.

being increasingly employed as marker of early atherosclerosis and vascular risk. ${ }^{2}$ The gold standard for measurement of atherosclerosis is Magnetic Resonance Imaging, which is neither freely available nor cost effective. ${ }^{12}$

Mean age of our patients and females which constituted $70 \%$ was similar to study done by Mahajan et al. ${ }^{13}$ Pattern of age and gender was similar to that seen in a study done in this population previously and worldwide. ${ }^{14,15-17}$ Mean duration of illness in our patients was 5.7 years while it was $8.03 \pm 5.48$ years in earlier studies. ${ }^{10,13-14}$ Sero-positive patients constituted $87.2 \%$ being similar to an earlier study, though in some studies it was around 35\%. Moreover percentage of patients on various medications was similar to other studies as well. ${ }^{16-17}$

Patients above 40 years and duration of illness $>5$ years had higher CIMT which is in accordance to the studies conducted earlier. ${ }^{18-19}$ Gender difference did not show any significant difference in CIMT between study and control group. There was no such study available for comparison. On subgroup analysis, BMI showed significant influence on 
CIMT which was in contrast to that observed by Del Rencon et al. ${ }^{7}$ Various studies have shown significant increase in CIMT in patients with high DAS. ${ }^{1,16,20-21}$ But in our study there was no such influence observed, which is also in accordance to the observation made by Carotti et al, ${ }^{18}$ probably because of score recorded in the first week. Effect of erosions on CIMT was also insignificant in contrast to study done by Kumeda et al. ${ }^{22}$ This could be because of smaller size of our study or use of different method of documentation.

Marker of inflammation, ESR was found to be associated with increase in CIMT although this association could not be observed in subgroup analysis and association is conflicting in various other studies as well. ${ }^{20,23-26}$ CRP positivity in our study had no impact on CIMT in contrast to other studies, ${ }^{16,25,27-28}$ reason could be that high sensitivity CRP was not measured in our sample which could have shown the true reflection. Long half life of ESR as compared to CRP could also explain our observation. Serum triglycerides even in normal ranges showed positive correlation with CIMT in our patients as was also observed by Cuomo, et al. ${ }^{29}$ This observation needs further study. In our study, it could probably be because of steroids or DMARDs use or female preponderance in whom there is lesser burden of atherosclerotic cardiovascular disease. This observation might point to the fact that even normal levels are not protective.

Patients on NSAIDs had higher CIMT although not statistically significant $(p 0.674)$. This has been seen in earlier studies as well implicating that this could lead to increased risk of cardiovascular disease, infarction and heart failure. ${ }^{30-31}$ Kumeda, et al observed no difference on CIMT in patients on various medications. ${ }^{22}$ There was no effect of DMARDs in our study as compared to previous study, ${ }^{16}$ possibly we took all drugs as one category. Patients on ayurvedic medications had higher CIMT; however, no study was available for comparison.

Twenty four $(60 \%)$ of our patients had significantly abnormal CIMT as compared to controls. Only one (5\%) control had abnormal CIMT. The frequency of abnormal CIMT in our patient population was much higher than that observed by Grover, et al (33.4\%), ${ }^{10}$ and Mahajan, et al (21\%). ${ }^{13}$ This higher incidence could be explained by geographical variation and our patients being mostly referred with severe disease than those in the community. This could also be because of higher age at the time of enrollment and greater duration of disease; this observation needs further study in our population. Tyrrel, et al in his meta-analysis observed significantly increased CIMT in autoimmune disorders including rheumatoid arthritis patients. ${ }^{32}$ Similar observation of increased prevalence and higher severity of CIMT especially in bulb-ICA (Internal Carotid Artery) was made by another study as well. ${ }^{33}$

The studies that failed to show an increase in carotid atherosclerosis in RA in past were relatively small and used varying methods. ${ }^{22,26}$ One study even large enough took more men, age $>60$ years, having severe hypertention, diabetes mellitus (10\%) and hypercholesterolemia (13\%). ${ }^{31}$

In conclusion, rheumatoid arthritis patients have definite evidence of accelerated atherosclerosis in absence of traditional risk factors owing to inflammation. This is comparable to what is seen in other populations' globally. BMI and serum triglycerides even in normal range showed significant influence in acceleration of atherosclerosis in these patients. Various other factors like age $>40$ years, male gender, longer duration of disease, BMI, elevated DAS-28 score, ESR, CRP positivity and erosions showed positive correlation though not statistically significant. B-mode ultrasonography is simple, non-invasive, and one of the sensitive methods to detect earlier atherosclerotic changes in them.

\section{Conflict of interest:}

The authors declare that they have no conflicting interest, support or funding from any agency.

\section{References}

1. Libby $\mathrm{P}$. The pathogenesis, prevention, and treatment of atherosclerosis. In: Harrison's principle of internal medicine. New York: McGraw-Hill. 17th ed. 2008; 2: 2252-8.

2. Doornum S, McColl G, Wicks IP. Accelerated atherosclerosis-an extra-articular feature of rheumatoid arthritis. Arthritis and Rheum 2002;46:862-73.

3. Pasceri V, Yeh ETH. A tale of two diseases: Atherosclerosis and rheumatoid arthritis. Circulation 1999;100:2124-6.

4. Cathcart ES, Spondick DH. Rheumatoid heart disease. A study of the incidence and nature of cardiac lesion in rheumatoid arthritis. N Engl J Med 1962;266:959-64.

5. Allebeck P. Increased mortality in rheumatoid arthritis. Scand J Reumatol 1982;11:81-6

6. Pincus T, Callahan IF, Sale WG. Severe functional declines, work disability and increased mortality in 75 rheumatoid arthritis patients studied over 9 years. Arthritis and Rheum 1984;27:864-72.

7. Del Rincon I, Williams's K, Stern MP, Freeman GL, O'Leary DH, Escalante A. High risk of cardiovascular events in a rheumatoid arthritis cohort not explained by traditional cardiac risk factors. Arthritis and Rheum 2001; 44:2737-45.

8. Prevoo ML, Van Hoff MA, Kuper HM. Modified disease activity scores that include twenty eight joint count, development and validation in a prospective longitudinal study of patients of rheumatoid arthritis. Arthritis and Rheum 1995;38:44-8.

9. Mannami T, Konishi M, Baba S, Nishi N, Terao A. Prevalence of asymptomatic carotid atherosclerotic lesion detected by high resolution ultrasonography and its 
relation to cardiovascular risk factors in the general population in Japanese city- A Suita study. Stroke 1997;28: 518-27.

10. Grover S, Sinha RP, Singh U, Tewari S, Aggarwal A, Misra R. Subclinical atherosclerosis in rheumatoid arthritis in India.J Rheumatol 2006;33:244-7.

11. Del Rincon I, Williams K, Stern MP, Freeman GL, O'Leary $\mathrm{DH}$, Escalante A. Association between carotid atherosclerosis and markers of inflammation in rheumatoid arthritis patients and healthy subjects. Arthritis and Rheum 2003; 48:1833-40.

12. Saam T, Underhill HR, Chu B, Takaya N, Cai J, Polissar NL, et al. Prevalence of American Heart Association Type VI Carotid Atherosclerotic Lesions Identified by Magnetic Resonance Imaging for Different Levels of Stenosis as Measure by Duplex Ultrasound. J Am Coll Cardiol 2008; 51:1014-2.

13. Mahajan V, Handa R, Kumar U, et al. Assessment of atherosclerosis by carotid intima-media thickness in patients with rheumatoid arthritis. JAPI 2008;56:587-90.

14. Buhroo AM, Baba AN. Adverse effects of low dose methotrexate in patients with rheumatoid arthritis. IJPMR 2006;17:21-5.

15. Coaccioli S, Capitò G, Valentini M, Pinoca F, Landucci P, Falati G, et al. Intima-media thickness of common carotid as cardiovascular risk factor in rheumatoid arthritis and metabolic disorders. Clin Ter 2007;158:505-8.

16. Dessein PH, Joffe BI and Singh S. Biomarkers of endothelial dysfunction, cardiovascular risk factors and atherosclerosis in rheumatoid arthritis. Arthritis Res Ther 2005;7: R634-43.

17. Johnsen SP, Larsson H, Tarone RE, McLaughlin JK, Nørgård B, Friis S, et al. Carefully controlled study show that all class of non-aspirin NSAIDs cause increased risk of myocardial infarction. Arch Intern Med 2005;165:978-8.

18. Carotti M, Salaffi F, Mangiacotti M, Cerioni A, Giuseppetti GM, Grassi W. Atherosclerosis in rheumatoid arthritis: the role of high-resolution B-mode ultrasound in the measurement of the arterial intima-media thickness. Reumatismo 2007;59:38-49.

19. Arnett FC, Edworthy SM, McShane DJ, et al. The American Rheumatism Association revised criteria for classification of rheumatoid arthritis. Arthritis Rheum 1988; 31:315-24.

20. Sattar N, McCarey DW, Capell H, McInnes LB. Explaining how "High-Grade" systemic inflammation accelerates vascular risk in rheumatoid arthritis. Circulation 2003; 108:2957-63.

21. Hannawi S, Haluska B, Marwick TH and Thomas R. Atherosclerotic disease is increased in recent-onset rheumatoid arthritis: a critical role for inflammation. Arthritis Res Ther 2007; 9(6):R116.
22. Kumeda Y, Inaba M, Goto H, Nagata M, Henmi Y, Furumitsu Y, et al. Increased thickness of the arterial intimamedia detected by ultrasonography in patients with rheumatoid arthritis. Arthritis Rheum 2002;46:1489-97.

23. Jadhav UM, Kadam NN. Impact of glycosylated hemoglobin on atherosclerosis - context with carotid intimamedia thickening (IMT) APICON - 2002. Free Papers Session Platform Presentation.

24. Keser G, Aksu K, Tamsel S, Ozmen M, Kitapcioglu G, Kabaroglu C, et al. Increased thickness of the carotid artery intima-media assessed by ultrasonography in behcet's disease. Clinical and Experimental Rheumatology 2005;23:S71-6.

25. Cao JJ, Arnold AM, Manolio TA, Polak JF, Psaty BM, Hirsch CH, et al. Association of carotid artery intimamedia thickness, plaques, and C-reactive protein with future cardiovascular disease and all-cause mortality: the Cardiovascular Health Study. Circulation 2007;116:32-8.

26. Jonsson CW, Backman C, Johnson O, Karp K, Lundström E, Sundqvist KG, et al. Increased prevalence of atherosclerosis in patients with medium term rheumatoid arthritis. $J$ Rheumatol 2001;28:2597-602.

27. Nikić P, Savić M, Zarić N and Durić D. Common carotid artery intima-media thickness, carotid atherosclerosis and subtypes of ischemic cerebral disease. Med Pregl 2003;56: 85-91.

28. Abu-Shakra M, Polychuck I, Szendro G, Bolotin A, Jonathan BS, Flusser D, et al. Duplex study of the carotid and femoral arteries of patients with rheumatoid arthritis: a controlled study. Semin Arthritis Rheum 2005;35:18-23.

29. Cuomo G, Di Micco P, Niglio A, Montagna GL,Valentini G. Atherosclerosis and rheumatoid arthritis: relationships between intima-media thickness of the common carotid arteries and disease activity and disability. Reumatismo 2004; 56:242-6.

30. Wållberg-Jonsson S, Ohman M and Rantapää-Dahlqvist $\mathrm{S}$. Which factors are related to the presence of atherosclerosis in rheumatoid arthritis? Scand J Rheumatol 2004; 33:373-9.

31. Bennett JS, Daugherty A, Herrington D, Greenland P, Roberts H , Taubert K. The Use of Nonsteroidal AntiInflammatory Drugs (NSAIDs). Circulation 2005; 111: 1713-6.

32. Tyrrell PN, Beyene J, Feldman BM, McCrindle BW, Silverman ED, Bradley TJ. Rheumatic disease and carotid intima-media thickness: a systematic review and metaanalysis. Arterioscler Thromb Vasc Biol 2010;30:892-3.

33. Kobayashi H, Giles JT, PolakJF, Blumenthal RS, Leffell MS, Szklo M, et al. Increased prevalence of carotid artery atherosclerosis in rheumatoid arthritis is artery-specific. $J$ Rheumatol 2010;37:890-3. 